Research Article

\title{
A study to assess the stigma related to tuberculosis among directly observed treatment short-course (DOTS) providers and patients on DOTS therapy attending DOTS centres of Mandya City, Karnataka, India
}

\author{
Nishita Padmanabhan ${ }^{1}$, Poornima S. ${ }^{2}$ \\ ${ }^{1}$ House surgeon, Mandya Institute of Medical Sciences, Mandya, Karnataka, India \\ ${ }^{2}$ Department of Community Medicine, Mandya Institute of Medical Sciences, Mandya, Karnataka, India
}

Received: 30 July 2016

Accepted: 31 August 2016

*Correspondence:

Dr. Nishita Padmanabhan,

E-mail: nishunaidu@yahoo.com

Copyright: () the author(s), publisher and licensee Medip Academy. This is an open-access article distributed under the terms of the Creative Commons Attribution Non-Commercial License, which permits unrestricted non-commercial use, distribution, and reproduction in any medium, provided the original work is properly cited.

\begin{abstract}
Background: Stigma is defined as a "powerful and tainting social label that radically changes the way individuals view themselves and are viewed by others". Tuberculosis is the second leading cause of death from an infectious disease. In India, social stigma attached to tuberculosis hinders patients from seeking adequate treatment interventions thus adding to the burden of disease.

Methods: All the patients receiving DOTS therapy for pulmonary and or extra pulmonary tuberculosis at DOTS Centres at Mandya Institute of Medical Sciences (MIMS), primary health care centres (PHCs) Guthalu and Kyathamgere were interviewed using Explanatory Model Interview Catalogue (EMIC) stigma scale. During the study period there were 33, 17 and 11 patients receiving DOTS therapy at MIMS, PHC Guthalu and PHC Kyathamgere respectively. A total of 18 DOT providers were interviewed using Social Distance Scale (SDS).

Results: $21(34.43 \%)$ of the 61 DOTS patients were found to be stigmatised and $40(65.57 \%)$ were not stigmatised. 10 $(47.62 \%)$ females and $11(27.5 \%)$ males were found to be stigmatised. $43(70.49 \%)$ patients preferred to keep other people from knowing that they were suffering from tuberculosis. 27(44.26\%) patients had decided to stay away from work/social groups and 26(42.62\%) felt that others give them less respect.

$14(77.78 \%)$ of the 18 DOT providers were definitely unwilling to have someone with tuberculosis as a caretaker of their children for a couple of hours.

Conclusions: One-third of the patients on DOTS therapy were stigmatised and three-fourth of the DOT providers reported stigma.
\end{abstract}

Keywords: Stigma, EMIC, Tuberculosis, DOTS patients, DOTS providers

\section{INTRODUCTION}

Tuberculosis is an infectious disease caused by Mycobacterium tuberculosis. ${ }^{1}$ It can affect every organ of the body except nail and hair but usually affects the lungs (pulmonary tuberculosis), although other organs may also be involved (extra-pulmonary tuberculosis). ${ }^{1}$
Transmission commonly takes place through airborne spread of droplet nuclei from a person with infectious pulmonary tuberculosis. ${ }^{1}$

Tuberculosis is the second leading cause of death from an infectious disease second only to human immunodeficiency virus (HIV). In 2013, 9 million people 
suffered from Tuberculosis worldwide, including 1.1 million cases among people living with $\mathrm{HIV}^{2}$ Effective diagnosis and treatment has saved 37 million lives between 2000 and 2013. Despite this, tuberculosis continues to be a major health problem. An estimated 1.5 million people died from Tuberculosis worldwide, including 360,000 among HIV positive patients. ${ }^{2} 13 \%$ of new tuberculosis cases were found to be HIV positive in 2013. High burden countries account for about $80 \%$ of the world's tuberculosis cases. The South East Asia and Western Pacific regions collectively accounted for $56 \%$ of all cases. Since 1990, the tuberculosis mortality rate has fallen by $45 \%$ and the tuberculosis prevalence rate by $41 \% .^{2}$

Although the burden of disease is higher among men, an estimated 3.3 million new cases of tuberculosis and 510,000 deaths due to tuberculosis were reported among women. This includes 180,000 HIV associated tuberculosis deaths. The total number of new and relapsing cases among children (defined as people aged $<15$ years) was $275,000 .^{2}$

At the turn of the $21^{\text {st }}$ century, tuberculosis was included as a part of the Millennium Developmental Goal 6. The target to reduce tuberculosis incidence rate by 2015 has already been met. However, the targets to halve prevalence and mortality rates by 2015 are yet to be achieved. $^{2}$

India is the highest TB burden country in the world, and also the largest number of cases, accounting for about $24 \%$ of the total global cases. 2 It is estimated that there are two deaths occurring from tuberculosis every three minutes in India. ${ }^{3}$ The estimated prevalence and incidence rates for 2013 were 211 and 171 cases per 100,000 population respectively. ${ }^{2}$ The targets of falling tuberculosis incidence rate and halving prevalence have been achieved in India. The target to halve the mortality rate is on track. It is likely to be achieved by 2015 based on the current predicted trend.

Tuberculosis is a classic example of a disease with both social and medical dimensions, characterised by its close relation to poor socioeconomic conditions. ${ }^{4}$ In India, social stigma attached to tuberculosis hinders patients from seeking adequate treatment interventions thus adding to the burden of disease. Perceived stigma is seen in leprosy, HIV/AIDS, mental illness, disability, epilepsy, sexually transmitted infections and many other health conditions. 5

Stigma is defined as a "powerful and tainting social label that radically changes the way individuals view themselves and are viewed by others". ${ }^{6}$ Social stigma has been recognised as an important barrier that delays initiation and adherence to treatment thereby adding to the disease burden. ${ }^{7}$ Stigma may limit social participation and lead to social exclusion which may result in an economic burden for the household and thus aggravate poverty. ${ }^{8}$ Non-disclosure to family means loss of emotional support which takes an emotional toll on the affected person. ${ }^{5}$ Stigma hinders effective treatment as they do not seek help for fear of social exclusion. This delays diagnosis and treatment, which may prolong transmission in the community. Patients who reveal their disease to the community may be looked down upon or rejected by the community. ${ }^{4}$

Clinical attendance may lead to awkward questions thus preventing patients from adhering to the treatment. ${ }^{5}$ Stigma among providers is likely to affect health programmes. Overall, stigma has a negative impact on the patient, provider and community.

Tuberculosis related stigma remains poorly understood in the developing world and the data on assessment of stigma is scarce. Hence, the present study was undertaken to investigate the level of perceived and enacted stigma experienced by DOTS patients and also their care providers.

\section{Aims and objectives}

To assess the perceived stigma about tuberculosis among patients on DOTS therapy attending DOTS Centres of Mandya City using Explanatory Model Interview Catalogue (EMIC) stigma scale.

To assess stigma related to tuberculosis among the providers of DOTS at DOTS Centres of Mandya City using Social Distance Scale (SDS).

\section{METHODS}

\section{Study design}

It is a hospital based cross sectional study

\section{Study setting}

Mandya city with a population of 137,735 has 3 DOTS Centres located at Mandya Institute of Medical Sciences (MIMS), primary health care centres (PHCs) Guthalu and Kyathamgere.

\section{Study period}

Study was conducted for 2 months (May 2015-June 2015)

\section{Sample size}

All the patients receiving DOTS therapy for pulmonary and or extra pulmonary tuberculosis at the above mentioned Centres were included for the study. During the study period there were 33,17 and 11 patients receiving DOTS therapy at MIMS, PHC Guthalu and PHC Kyathamgere respectively. 
The providers of DOTS therapy at these Centres were included for assessing the stigma related to tuberculosis. There were a total of 18 DOT providers at these DOTS Centres.

\section{Inclusion criteria}

- All the patients receiving DOTS therapy for pulmonary/extra pulmonary tuberculosis at the DOTS Centres of Mandya city during the study period.

- All the providers of DOTS therapy at MIMS, PHC Guthalu and PHC Kyathamgere.

\section{Exclusion criteria}

- Patients and DOT providers refusing to consent for the study.

\section{Data collection procedure}

Personal interview of the patients and the DOTS providers by a trained person to assess the stigma using pretested questionnaires after taking informed consent.

\section{Study tools/instruments used}

Explanatory Model Interview Catalogue (EMIC) stigma scale and Social Distance Scale (SDS) Explanatory Model Interview Catalogue (EMIC) was developed by Weiss et al, later adapted by International Federation of Anti-Leprosy Association (ILEP) specifically for leprosy. EMIC measures the patient's fear of discrimination and awareness of negative attitudes as perceived or anticipated stigma. ${ }^{5}$ EMIC also assesses the severity and the widespread nature of stigma. EMIC questionnaire has a fixed series of 15 questions, the responses for which are coded on a numerical scale ranging from $0-3$ where $0=$ No, $1=$ Uncertain, $2=$ Possibly and $3=$ Yes. The scores of all the questions should be added up to get a sum score. The outcome score indicates the perceived stigma. The higher the score, the higher the level of perceived stigma. EMIC is available in multiple languages, including: English, Marathi, Bengali, Tamil, etc. The Kannada version of EMIC was developed, translated and validated by National Institute of Mental Health and Neurosciences (NIMHANS), Bangalore. This EMIC questionnaire was specifically modified for tuberculosis and adapted.

Social distance scale (SDS) measures the stigma from the perspective of the stigmatiser. The prototype of SDS questionnaire was developed by Emory $\mathrm{S}$ Bogardus from Brock University for mental illnesses, later modified and adapted for use in leprosy by ILEP. SDS questionnaire assesses provider's expression as to how close they are willing to be with a person affected. ${ }^{5}$ The SDS questionnaire consists of 6 questions, each of them with 4 options on a Likert scale ranging from 'definitely willing', 'probably willing', 'probably unwilling' to 'definitely unwilling'. The social distance score is calculated by summing up to create a total sum score. Higher mean score indicates tendency on the part of providers to keep more social distance from the person affected by a disease condition.

\section{Plan of analysis/statistical tools}

Data was entered into Microsoft Excel 2010and summarized using percentages, proportions and appropriate statistical tests.

\section{Confidentiality}

Adequate privacy was ensured for the interview. Informed consent was taken. Data collected from the individuals will be kept confidential and shall be used for academic teaching and training purposes only. In case of publication of the data, care will be exercised to not reveal the patient identity.

\section{Ethical consideration}

Ethical clearance was obtained from MIMS Institutional Ethics Committee before beginning the study. Letter of permission no. MIMS/IEC/2014-15dated 14.03.2015.

\section{RESULTS}

During the study period there were 33,17 and 11 patients receiving DOTS therapy at MIMS, PHC Guthalu and PHC Kyathamgere respectively. There were a total of 18 DOT providers at these DOTS Centres.

\section{Explanatory model interview catalogue (EMIC) stigma scale for the patient}

Among 61 study participants, $40(65.57 \%)$ were males and $21(34.43 \%)$ were females. $44(72.13 \%)$ of the total 61 candidates were aged between 31 and 60 years. 52 were married and 44 were literate (Table 1 ).

The total obtainable score was 45 and the least score was 0 . A score of 22.5 or higher was considered as stigmatised. 21 respondents were found to experience stigma.

$10(47.62 \%)$ females were found to be stigmatised and 11 $(27.5 \%)$ males were stigmatised. As many as $6(40 \%)$ manual unskilled workers, 5 (33.33) manual skilled workers, $5(33.33 \%)$ students/homemakers, $3(60 \%)$ service/sales workers and $2(18.18 \%)$ unemployed persons were found to experienced stigma. $2(50 \%)$ graduates, $3(37.5 \%)$ diploma holders, 6 (35.29\%) high school educated, $3(20 \%)$ primary school and $7(41.18 \%)$ illiterates were stigmatised. It was found that $16(30.77 \%)$ married persons and $5(55.56 \%)$ unmarried were stigmatised (Table 1).

$43(70.49 \%)$ patients preferred to keep other people from knowing that they were suffering from tuberculosis and 
$15(24.59 \%)$ did not. On a more positive note, as many as $46(75.41 \%)$ of the patients had discussed this problem with the person closest to them and $15(24.59 \%)$ did not $17(27.87 \%)$ of the patients thought less of themselves/felt inferior to those who don't have tuberculosis. $5(8.20 \%)$ felt they may possibly feel inferior while $2(3.28 \%)$ were uncertain. On the other hand, 37 (60.66\%) did not feel inferior (Table 2).

$14(22.95 \%)$ patients confided that they have been made to feel ashamed or embarrassed because of this problem.
While $40(65.57 \%)$ did not, $6(9.84 \%)$ said they may possibly feel ashamed and only $1(1.64 \%)$ was uncertain. $26(42.62 \%)$ patients felt that others give them less respect. $6(9.84 \%)$ felt they may possibly receive less respect while $4(6.56 \%)$ were uncertain. $25(40.98 \%)$ of the patients did not feel that they received lesser respect. Only $13(21.31 \%)$ believed their disease might have bad effects on those around them even after they have been treated. $9(14.75 \%)$ of them thought there could possibly be bad effects on others even after treatment and 3 $(4.92 \%)$ were uncertain (Table 2 ).

Table 1: Socio-demographic details of patients receiving dots therapy $(n=61)$.

\begin{tabular}{|llll|}
\hline Parameter & Number $(\%)$ & Stigma experienced & Stigma not experienced \\
\hline Age (in years) & & & $3(60.00)$ \\
\hline $11-20$ & $5(8.20)$ & $2(40.00)$ & $3(42.86)$ \\
\hline $21-30$ & $7(11.48)$ & $4(57.14)$ & $11(69.75)$ \\
\hline $31-40$ & $16(26.23)$ & $5(31.25)$ & $13(72.22)$ \\
\hline $41-50$ & $18(29.51)$ & $5(27.78)$ & $7(70.00)$ \\
\hline $51-60$ & $10(16.39)$ & $3(30.00)$ & $2(66.67)$ \\
\hline $61-70$ & $3(4.92)$ & $1(33.33)$ & $1(50.00)$ \\
\hline$>70$ & $2(3.28)$ & $1(50.00)$ & $29(72.5)$ \\
\hline Sex & & & $11(52.38)$ \\
\hline Male & $40(65.57)$ & $11(27.5)$ & 0 \\
\hline Female & $21(34.43)$ & $10(47.62)$ & $2(40.00)$ \\
\hline Occupation & & & $10(66.67)$ \\
\hline Professional & 0 & 0 & $9(60.00)$ \\
\hline Service/ Sales & $5(8.20)$ & $3(60.00)$ & $10(66.67)$ \\
\hline Manual skilled & $15(24.59)$ & $5(33.33)$ & $9(81.82)$ \\
\hline Manual unskilled & $15(24.59)$ & $6(40.00)$ & $2(50.00)$ \\
\hline Students/Home makers & $15(24.59)$ & $5(33.33)$ & $5(62.50)$ \\
\hline Unemployed & $11(18.03)$ & $2(18.18)$ & $11(64.71)$ \\
\hline Education & & & $12(80.00)$ \\
\hline Graduate & $4(6.56)$ & $2(50.00)$ & $10(58.82)$ \\
\hline College & $8(13.11)$ & $3(37.50)$ & $36(69.23)$ \\
\hline High School & $17(27.87)$ & $6(35.29)$ & $4(44.44)$ \\
\hline Primary School & $15(24.59)$ & $3(20.00)$ & \\
\hline Illiterate & $17(27.87)$ & $7(41.18)$ & \\
\hline Marital status & & $16(30.77)$ & $5(55.56)$ \\
\hline Married & $52(85.25)$ & & \\
\hline Unmarried & $9(14.75)$ & & \\
\hline Avage & & & \\
\hline & & & \\
\hline & & & \\
\hline
\end{tabular}

Average age $=42.44$ years.

$18(29.51 \%)$ patients felt that others have avoided them because of this problem and $41(67.21 \%)$ did not feel so. $19(31.15 \%)$ patients believed that others refused to visit their homes due to this problem. $2(3.28 \%)$ were uncertain while $9(14.75 \%)$ believed it could possibly be the reason. $31(50.82 \%)$ of them believed that there was no relationship between this and people refusing to visit their homes.18 $(29.51 \%)$ were of the opinion that others would think less of their family if they knew. 10 $(16.39 \%)$ believed that this could possibly cause people to think less of their family, $4(6.56 \%)$ were uncertain and $29(47.54 \%)$ believed that this would not cause people to think less of their family (Table 2).

A total of $12(19.67 \%)$ anticipated difficulties in getting married or were experiencing problems in their current marriage. $2(3.28 \%)$ possibly anticipated problems, 1 $(1.64 \%)$ was uncertain and $46(75.41 \%)$ believed there were no difficulties caused by this in marriage \& marital life. $14(22.95 \%)$ patients thought this would cause social 
problems for their children in the community. $5(8.20 \%)$ were uncertain and $5(8.20 \%)$ believed that it could possibly cause problems for their children. $37(60.66 \%)$ did not believe that this would cause any problems for their children in the community. $16(26.23 \%)$ patients felt that this disease makes it difficult for someone else in their family to get married. $10(16.39 \%)$ believed that this could possibly cause difficulty in getting married for someone else in their family, 5(8.20\%) were uncertain and $30(49.18 \%)$ believed there would be no such problems (Table 2).

$20(32.79 \%)$ patients had been asked to stay away from work/social groups while $27(44.26 \%)$ had decided to stay away on their own. Only $3(4.92 \%)$ patients thought that they might also have other health problems because of tuberculosis. $54(88.52 \%)$ patients did not presume other health problems (Table 2).
$21(34.43 \%)$ of the 61 respondents were found to be stigmatised and $40(65.57 \%)$ were not stigmatised (Figure 1).

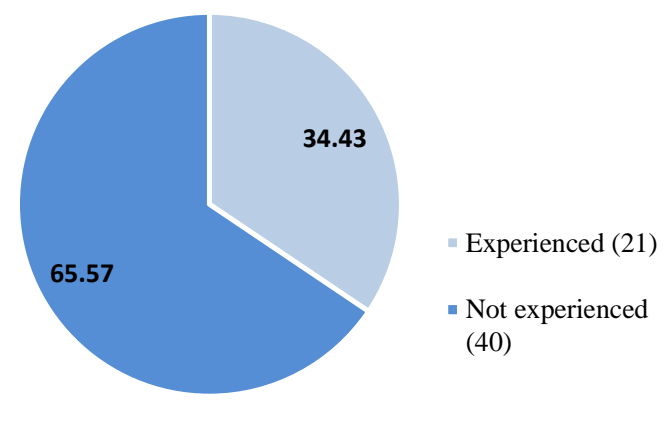

Figure 1: Distribution of study subjects experiencing stigma.

Table 2: Summary of EMIC stigma scale questionnaire for perceived stigma (n=61).

\begin{tabular}{|c|c|c|c|c|c|}
\hline \multirow{2}{*}{$\begin{array}{l}\text { Serial } \\
\text { No. }\end{array}$} & \multirow{2}{*}{ Question } & \multicolumn{4}{|c|}{ Total number of participants ( $\%$ ) } \\
\hline & & $\mathbf{0}$ & 1 & 2 & 3 \\
\hline 1 & Desire to keep others from knowing & $15(24.59)$ & $2(3.28)$ & $1(1.64)$ & $43(70.49)$ \\
\hline $2 *$ & Have discussed with person closest to you & $15(24.59)$ & 0 & 0 & $46(75.41)$ \\
\hline 3 & Think less of yourself/Feel inferior to others & $37(60.66)$ & $2(3.28)$ & $5(8.20)$ & $17(27.87)$ \\
\hline 4 & Ashamed/Embarrassed & $40(65.57)$ & $1(1.64)$ & $6(9.84)$ & $14(22.95)$ \\
\hline 5 & Others give less respect & 25(40.98) & $4(6.56)$ & $6(9.84)$ & $26(42.62)$ \\
\hline 6 & $\begin{array}{l}\text { Adverse effect on others around you even after you } \\
\text { have been treated }\end{array}$ & $36(59.02)$ & $3(4.92)$ & $9(14.75)$ & $13(21.31)$ \\
\hline 7 & Others have avoided you & $41(67.21)$ & $1(1.64)$ & $1(1.64)$ & $18(29.51)$ \\
\hline 8 & Others refuse to visit & $31(50.82)$ & $2(3.28)$ & $9(14.75)$ & $19(31.15)$ \\
\hline 9 & Others would think less of your family & $29(47.54)$ & $4(6.56)$ & $10(16.39)$ & $18(29.51)$ \\
\hline 10 & Problem getting married/Problems in marriage & $46(75.41)$ & $1(1.64)$ & $2(3.28)$ & $12(19.67)$ \\
\hline 11 & Social problems for your children in the community & $37(60.66)$ & $5(8.20)$ & $5(8.20)$ & $14(22.95)$ \\
\hline 12 & Problem for someone else in the family to marry & $30(49.18)$ & $5(8.20)$ & $10(16.39)$ & $16(26.23)$ \\
\hline 13 & Asked to stay away from work or social groups & $41(67.21)$ & 0 & 0 & $20(32.79)$ \\
\hline 14 & Decided to stay away from work or social groups & $30(49.18)$ & $3(4.92)$ & $1(1.64)$ & $27(44.26)$ \\
\hline 15 & Presumed other health problems & $54(88.52)$ & $3(4.92)$ & $1(1.64)$ & $3(4.92)$ \\
\hline
\end{tabular}

$0=$ No, $1=$ Uncertain, $2=$ Possibly and $3=$ Yes $*$ Question 2 is reverse coded as $3=0,2=1,1=2,0=3$.

Table 3: Distribution of DOTS patients according to treatment category and stigma experienced.

\begin{tabular}{|llll|}
\hline $\begin{array}{l}\text { Treatment } \\
\text { category }\end{array}$ & $\begin{array}{l}\text { Number } \\
(\%)\end{array}$ & $\begin{array}{l}\text { Stigma } \\
\text { experienced } \\
\text { n }(\%)\end{array}$ & $\begin{array}{l}\text { Stigma not } \\
\text { experienced } \\
\text { n }(\%)\end{array}$ \\
\hline Category 1 & $57(93.44)$ & $20(35.09)$ & $37(64.91)$ \\
\hline Category 2 & $4(6.55)$ & $1(25.00)$ & $3(75.00)$ \\
\hline
\end{tabular}

Of the 57 patients on category 1 treatment, $20(35.09 \%)$ were found to be stigmatised and $1(25.00 \%)$ of the 4 category 2 patients were stigmatised (Table 3 ).
Table 4: Distribution of DOTS patients according to disease category and stigma experienced.

\begin{tabular}{|llll|}
\hline $\begin{array}{l}\text { Disease } \\
\text { category }\end{array}$ & $\begin{array}{l}\text { Number } \\
(\%)\end{array}$ & $\begin{array}{l}\text { Stigma } \\
\text { experienced } \\
\text { n }(\%)\end{array}$ & $\begin{array}{l}\text { Stigma not } \\
\text { experienced } \\
\text { n }(\%)\end{array}$ \\
\hline Pulmonary TB & $\begin{array}{l}48 \\
(78.69)\end{array}$ & $\begin{array}{l}18 \\
(37.50)\end{array}$ & $\begin{array}{l}30 \\
(62.50)\end{array}$ \\
\hline $\begin{array}{l}\text { Extra- } \\
\text { pulmonary TB }\end{array}$ & 13 & 3 & 10 \\
\hline
\end{tabular}

$18(37.50 \%)$ of 48 patients who had pulmonary tuberculosis and $3(23.08 \%)$ of 13 patients who had extrapulmonary tuberculosis were stigmatised (Table 4). 
$8(40.00 \%)$ of 20 patients in intensive phase of their treatment and $13(31.71 \%)$ of 41 patients in continuous phase of their treatment were found to be stigmatised. (Table 5).

Table 5: Distribution of DOTS patients according to treatment phase and stigma experienced.

\begin{tabular}{|llll|}
$\begin{array}{l}\text { Treatment } \\
\text { phase }\end{array}$ & $\begin{array}{l}\text { Number } \\
(\%)\end{array}$ & $\begin{array}{l}\text { Stigma } \\
\text { experienced } \\
\mathbf{n}(\%)\end{array}$ & $\begin{array}{l}\text { Stigma not } \\
\text { experienced } \\
\text { n }(\%)\end{array}$ \\
\hline Intensive & $20(32.79)$ & $8(40.00)$ & $12(60.00)$ \\
\hline Continuous & $41(67.21)$ & $13(31.71)$ & $28(68.29)$ \\
\hline
\end{tabular}

\section{Social distance scale (SDS) for the DOT provider}

18 DOTS providers were interviewed at MIMS DOTS Centre, PHC Kyathamgere and PHC Guthalu. Of these, 14 were aged between 31 and 50 years of age. 16 of these respondents were female and 16 were married. With regard to educational status of the DOTS providers, 8 were graduates, 4 had attended college, while 6 had only completed their high school (Table 6).

5 respondents answered that they were definitely willing to rent a room in their home to someone with tuberculosis while 2 were definitely unwilling. 11 were probably willing. When asked how they felt about having someone with tuberculosis as a neighbour, 10 responded saying that they were definitely willing, 5 were probably willing, 2 were probably unwilling and 1 was definitely unwilling (Table 7).

14 respondents were definitely unwilling to have someone with tuberculosis as a caretaker of their children for a couple of hours. Only 4 respondents were probably willing. On enquiring how they felt about having one of their children marry someone with tuberculosis 7 respondents said that they were definitely unwilling, 1 was probably willing, 9 were probably unwilling and only 1 was definitely willing (Table 7).
4 respondents were definitely willing to introduce someone with tuberculosis to a young woman that they are friendly with. 9 were probably willing, 1 was probably unwilling and 4 were definitely unwilling.11 respondents were definitely willing to recommend someone with tuberculosis for a job working for a friend of theirs, 6 were probably willing while only 1 was probably unwilling (Table 7).

Table 6: Socio-demographic details of DOT providers $(n=18)$.

\begin{tabular}{|lll|}
\hline Parameter & Number & Percentage \\
\hline Age (in years) & & \\
\hline $21-30$ & 3 & 16.67 \\
\hline $31-40$ & 5 & 27.78 \\
\hline $41-50$ & 9 & 50.00 \\
\hline $51-60$ & 1 & 5.55 \\
\hline Sex & & \\
\hline Male & 2 & 11.11 \\
\hline Female & 16 & 88.89 \\
\hline Occupation & & \\
\hline $\begin{array}{l}\text { Anganwadi } \\
\text { Worker }\end{array}$ & 8 & 44.44 \\
\hline Pharmacist & 2 & 11.11 \\
\hline TB Health Visitor & 2 & 11.11 \\
\hline Group D Worker & 2 & 11.11 \\
\hline Doctor & 1 & 5.55 \\
\hline Lab Technician & 1 & 5.55 \\
\hline Health Assistant & 1 & 5.55 \\
\hline $\begin{array}{l}\text { Jr. Health } \\
\text { Assistant }\end{array}$ & 1 & 5.55 \\
\hline Education & & \\
\hline Graduate & 8 & 11.11 \\
\hline College & 4 & 22.22 \\
\hline High School & 6 & 33.33 \\
\hline Marital status & & \\
\hline Married & 16 & \\
\hline Unmarried & 2 & \\
\hline Average age & & \\
\hline & & \\
\hline & & \\
\hline
\end{tabular}

Average age $=39.94$ years

Table 7: Summary of SDS responses of DOT providers.

\begin{tabular}{|c|c|c|c|c|}
\hline \multirow{2}{*}{ Question } & \multicolumn{4}{|c|}{ Total number of participants } \\
\hline & $\mathbf{0}$ & 1 & 2 & 3 \\
\hline Renting a room in your home to someone with tuberculosis & 5 & 11 & 0 & 2 \\
\hline Having someone with tuberculosis as a neighbour & 10 & 5 & 2 & 1 \\
\hline $\begin{array}{l}\text { Having someone with tuberculosis as a caretaker of your children } \\
\text { for a couple of hours }\end{array}$ & 0 & 4 & 0 & 14 \\
\hline Having one of your children marry someone with tuberculosis & 1 & 9 & 1 & 7 \\
\hline $\begin{array}{l}\text { Introducing someone with tuberculosis to a young woman you are } \\
\text { friendly with }\end{array}$ & 4 & 9 & 1 & 4 \\
\hline $\begin{array}{l}\text { Recommending someone with tuberculosis for a job working for a } \\
\text { friend of yours }\end{array}$ & 11 & 6 & 1 & 0 \\
\hline
\end{tabular}

$* 0=$ 'definitely willing', 1 = 'probably willing', 2 = 'probably unwilling' and 3 = 'definitely unwilling'. 


\section{DISCUSSION}

In our study, $21(34.43 \%)$ of the 61 respondents were found to be stigmatised and $40(65.57 \%)$ were not stigmatised. Findings showed that $47.62 \%$ females were found to be stigmatised whereas only $27.5 \%$ males were stigmatised. This is supported by the study conducted by Somma et al in Bangladesh, India, Malawi and Colombia which found that the psychosocial burden of tuberculosis related stigma is more among women. ${ }^{9}$ Another study done by Balasubramanian et al at Thiruvallur had presented similar findings. ${ }^{10}$

In our study, $32.79 \%$ had been asked to stay away from work/social groups, $44.26 \%$ had decided to stay away on their own and $42.62 \%$ felt that others give them less respect. These findings are similar to the study by Jaggarajamma et al at Kancheepuram (rural) and Chennai (urban) which found that one third of the patients were reluctant to attend social functions due to their illness. ${ }^{4}$ Also, more than one third felt that others looked down upon them. ${ }^{4}$ Jaggarajamma et al reported that $63 \%$ of unmarried patients expressed problems related to marriage prospects. Our study found that $19.67 \%$ of patients anticipated difficulties in getting married or were experiencing problems in their current marriage and $26.23 \%$ patients felt that this disease makes it difficult for someone else in their family to get married.

A study conducted by Aryal et al showed that patients who were dependent on others were found to be more stigmatised. ${ }^{8}$ However, in our study, $33.33 \%$ students/homemakers and $18.18 \%$ unemployed persons were found to have experienced stigma. Further, Aryal et al found that patients with extra-pulmonary tuberculosis were more stigmatised than those with pulmonary tuberculosis, whereas our study found that $37.50 \%$ patients who had pulmonary tuberculosis and $23.08 \%$ patients who had extra-pulmonary tuberculosis were stigmatised.

Aryal et al found that the patients in intensive phase of treatment experienced more stigma than those in the continuous phase. ${ }^{8}$ These findings are similar to our study findings where $40.00 \%$ patients in intensive phase and $31.71 \%$ patients in continuous phase of their treatment were found to be stigmatised. Aryal et al also found that $60.00 \%$ of the patients revealed that they did not want others to know about their disease status which was similar to our study finding of $70.90 \%$. $86.70 \%$ of patients had discussed their problem with someone in their study and $75.41 \%$ of patients had in our study.

Aryal et al reported that many patients felt ashamed/embarrassed and thought less of themselves. Our study found that $27.87 \%$ of patients thought less of themselves/felt inferior to those who don't have tuberculosis and $22.95 \%$ patients confided that they have been made to feel ashamed or embarrassed because of this problem.
A total of 18 DOTS providers were interviewed. 14 respondents were definitely unwilling to have someone with tuberculosis as a caretaker of their children for a couple of hours and only 4 respondents were probably willing. On enquiring how they felt about having one of their children marry someone with tuberculosis 7 respondents said that they were definitely unwilling and only 1 respondent was definitely willing. 4 respondents were definitely willing to introduce someone with tuberculosis to a young woman that they are friendly with while 4 of the respondents were definitely unwilling. 5 respondents answered that they were definitely willing to rent a room in their home to someone with tuberculosis while 2 were definitely unwilling. When asked how they felt about having someone with tuberculosis as a neighbour, 10 responded saying that they were definitely willing and 1 was definitely unwilling. 11 respondents were definitely willing to recommend someone with tuberculosis for a job working for a friend of theirs while only 1 was probably unwilling.

\section{CONCLUSION}

The study showed that one-third of the patients on DOTS therapy attending DOTS Centres of Mandya City were stigmatised. Findings showed that nearly half of the female respondents were found to be stigmatised whereas only a quarter of the males were stigmatised. In our study, one-third of the respondents had been asked to stay away from work/social groups. Nearly half of the respondents had decided to stay away from work/social groups on their own. Our study identified that two-fifths felt that others give them less respect. It was found that one-fifth of the patients anticipated difficulties in getting married or were experiencing problems in their current marriage and one-fourth of the patients felt that this disease makes it difficult for someone else in their family to get married. Three-fourth of the patients revealed that they did not want others to know about their disease and three-fourth of the patients had discussed their problem with someone. Our study showed that over one-fourth of patients thought less of themselves/felt inferior to those who don't have tuberculosis and nearly one-fourth of patients confided that they have been made to feel ashamed or embarrassed because of this problem. Around one-third of the patients on category 1 treatment were found to be stigmatised and one-fourth of the category 2 patients were stigmatised. In our study, close to two-fifths of the patients who had pulmonary tuberculosis and onefourth of the patients who had extra-pulmonary tuberculosis were found to be stigmatised. Two-fifths of the patients in intensive phase of their treatment and onethird of patients in continuous phase of their treatment were stigmatised.

Our study found that three-fourth of the respondents were definitely unwilling to have someone with tuberculosis as a caretaker of their children for a couple of hours and two-fifths of the respondents said that they were definitely unwilling to have one of their children marry 
someone with tuberculosis. One-fourth of the respondents were definitely willing to introduce someone with tuberculosis to a young woman that they are friendly with while one-fourth of the respondents were definitely unwilling. Our study found that over one-fourth of the providers of DOTS at DOTS Centres of Mandya City were definitely willing to rent a room in their home to someone with tuberculosis. Over half the respondents were definitely willing to have someone with tuberculosis as a neighbour. It was also found that over three-fifths of the respondents were definitely willing to recommend someone with tuberculosis for a job working for a friend of theirs.

\section{Suggestions}

Exclusive group discussion of patients and experience sharing through contact approach could be undertaken. Family counselling may be done to address marital issues and the impact on lives of children. Conduct of community awareness campaigns to address stigma at the community level.

Training of health workers to help them understand what stigma is and how it affects the patients. Organisation of role plays, screening of short films and advertising at quarterly review meetings.

\section{ACKNOWLEDGEMENTS}

Authors would like to acknowledge the Director, Medical Superintendent, faculty of department of Community Medicine of Mandya Institute of Medical Sciences and Medical Officers of DOTS Centres of Mandya city. We are also grateful to Dr M. Manjula, NIMHANS for providing the Kannada version of EMIC.

Funding: No funding sources Conflict of interest: None declared

Ethical approval: The study was approved by the Institutional Ethics Committee

\section{REFERENCES}

1. Raviglione MC, O’Brien RJ. Tuberculosis. Chapter 165 in Fauci AS, Braunwald E, Kasper DL, Hauser SL, Longo DL, Jameson JL, et al. Harrison's Principles Of Internal Medicine. 18thed. New York: McGraw Hill; 2012; p 1340-58.

2. World Health Organisation. Global Tuberculosis Report 2014. Geneva. Available on http://www.who.int/tb/publications/global_report/en /accessed on January 14, 2015.

3. TBC India. Available on http://www.tbcindia. nic.in/RNTCP. Html accessed on January 21, 2015.
4. Jaggarrajamma K, Ramchandran R, Charles N, Chandrasekaran V, Muniuandi M, Ganapathy S. Psycho- social dysfunction: Perceived and enacted stigma among tuberculosis patients registered under RNTCP. Indian J Tuberc. 2008;55:179-87.

5. International Federation of Anti-Leprosy Association (ILEP). Guidelines to reduce stigma. London. Available on http://www.ilep.org.uk/ library-resources/ infolep-information-services/ subjectguides/leprosy-related-stigma/accessed on January 12, 2015.

6. Alonzo AA, Reynolds NR. Stigma, HIV and AIDS: an exploration and elaboration of a stigma trajectory. Soc Sci Med. 1995;41(3):303-15.

7. Dhingra VK, Khan S. A Sociological Study On Stigma Among $\mathrm{Tb}$ Patients In Delhi. Indian J Tuberc. 2010;57:12-8.

8. Aryal S, Badhu A, Pandey S, Bhandari A, Khatiwoda P, Khatiwada P, et al. Stigma related to Tuberculosis among patients attending DOTS clinics of Dharan Municipality. Kathmandu Univ Med J. 2012;37(1)48-52.

9. Somma D, Thomas BE, Karim F, Kemp J, N. Arias $\mathrm{N}$, Auer C, et al. Gender and socio-cultural determinants of TB-related stigmain Bangladesh, India, Malawi and Colombia. Int J Tuberc Lung Dis. 2008;12(7):856-66.

10. Balasubramanian R, Garg R, Santha T, P. G. Gopi PG, Subramani R, Chandrasekaran V, et al. Gender disparities in tuberculosis: report from a rural DOTS programme in south India. Int $\mathbf{J}$ Tuberc Lung Dis. 2004;8(3):323-32.

11. Van Rie A, Sengupta S, Pungrassami P, Balthip Q, Choonuan S, Kasetjaroen Y, et al. Measuring stigma associated with tuberculosis and HIV/AIDS in southern Thailand: exploratory and confirmatory factor analyses of two new scales. Tropical Med and Int Health. 2008;13(1):21-30.

12. Coreil J, Lauzardo M, Heurtelou M. Anticipated tuberculosis Stigma among Health Professionals and Haitian Patients in South Florida. J Health Care Poor Underserved. 2012; 23(2): 636-50.

13. Dodor EA. Health Professionals Expose Tb Patients To Stigmatization In Society: Insights From Communities In An Urban District In Ghana. Ghana Med J. 2008;42(4):144-8.

Cite this article as: Padmanabhan N, Poornima S. A study to assess the stigma related to tuberculosis among directly observed treatment short-course (DOTS) providers and patients on DOTS therapy attending DOTS centres of Mandya City, Karnataka, India. Int J Community Med Public Health 2016;3:2817-24. 